decrease in the proportion undergoing surgery. With the advent of milder cases the difference in the risk of end points between surgically and conservatively treated patients must be larger than if the cases were more balanced. However, the effects of surgery on these mild cases must be expected to be less than those on the more severe cases in our study.

Contributors: See bmj.com

Funding: None.

Competing interests: None declared.

1 Vestergaard P, Mollerup CL, Frøkjær VG, Christiansen P, Blichert-Toft M, Mosekilde L. Cohort study of risk of fracture before and after surgery for primary hyperparathyroidism. BMJ 2000;321:598-602.

2 Mollerup CL, Vestergaard P, Frøkjær VG, Mosekilde L, Christiansen P, Blichert-Toft M. Risk of renal stone events in primary hyperparathyroidism before and after parathyroid surgery: controlled retrospective roidism before and after parathyroid

3 Sancho JJ, Roucho J, Riera-Vidal R, Sitges-Serra A. Long-term effects of parathyroidectomy for primary hyperparathyroidism on arterial hypertension. World J Surg 1992;16:732-6.

4 Stefenelli T, Abela C, Frank H, Koller-Strametz J, Niederle B. Time course of regression of left ventricular hypertrophy after successful parathyroidectomy. Surgery 1997;121:157-61.

5 Christiansen P, Steiniche T, Brixen K, Hessov I, Melsen F, Heickendorff L, et al. Primary hyperparathyroidism: effect of parathyroidectomy on regional bone mineral density in Danish patients: a three year follow-up tudy Bome 1999;25:589-95.

6 Rao D, Phillips ER, Divine GW, Talpos GB. Randomized controlled trial of surgery vs. no-surgery in patients with mild asymptomatic primary hyperparathyroidism: final report. J Bone Miner Res 2000;15(suppl 1): S164. [Abstract.]

7 Talpos GB, Bone HG III, Kleerekoper M, Phillips ER, Alam M, Honasoge $\mathrm{M}$, et al. Randomized trial of parathyroidectomy in mild asymptomatic primary hyperparathyroidism: patient description and effects on the SF-36 health survey. Surgery 2000;128:1013-20.

8 Andersen TF, Madsen M, Jørgensen J, Mellemkjær L, Olsen JH. The Danish National Hospital Register. Dan Med Bull 1999;46:263-8.

9 Jürgensen HJ, Frølund C, Gustafsen J, Mosbech H, Guldhammer B. [Registration of diagnoses in a national patient register. Preliminary assessment of the validity of the register]. Ugeskr Lager 1984;146:3303-8.

10 Mosbech J, Jørgensen J, Madsen M, Rostgaard K, Thornberg K, Poulsen TD. [The Danish National Patient Register: evaluation of data quality]. Ugeskr Lager 1995;157:3741-5.

11 Bilezikian JP, Potts JT Jr, Fuleihan GE, Kleerekoper M, Neer R, Peacock M, et al. Summary statement from a workshop on asymptomatic primary hyperparathyroidism: a perspective for the 21st century.J Bome Miner Res 2002; 17:N2-11.

12 Soreide JA, van Heerden JA, Grant CS, Yau Lo C, Schleck C, Ilstrup DM. Survival after surgical treatment for primary hyperparathyroidism. Surgery 1997;122:1117-23.

13 Wermers RA, Khosla S, Atkinson EJ, Hodgson SF, O'Fallon WM, Melton LJ III. The rise and fall of primary hyperparathyroidism: a population-based study in Rochester, Minnesota, 1965-1992. Ann Intern Med 1997;126:433-40.

(Accepted 9 July 2003)

\title{
Prehospital tracheal intubation in severely injured patients: a Danish observational study
}

\author{
Erika Frischknecht Christensen, Claus Christian Schovsbo Høyer
}

The value of advanced prehospital life support for patients with severe trauma-for example, endotracheal intubation by ambulance staff-is unclear. Only one randomised controlled trial was found among 2034 papers in a Cochrane review, concluding that advanced trauma life support by ambulance crews should be initiated only as part of rigorously conducted trials. ${ }^{1}$ A critical review also failed to show benefit and reported success rates for endotracheal intubation from $57 \%$ to $92 \%$. $^{2}$ The review questioned whether prehospital staff could master the required skills. These reviews focus on paramedic based systems.

The helicopter emergency medical services in London is staffed by doctors; the service studied 486 trauma patients intubated without anaesthesia at the scene. ${ }^{3}$ One patient $(0.2 \%)$ survived-after thoracotomy at the scene. The service debated the practice of paramedics doing endotracheal intubation without anaesthesia because this is possible only in profoundly unconscious trauma patients with a poor prognosis.

In Denmark, ambulance crews do not intubate, and emergency medicine is not a separate specialty. Anaesthetists work in emergency care in and out of hospitals.

We describe the number of severely injured patients having endotracheal intubation with and without anaesthetic drugs (hypnotics, analgesics, and muscle relaxants) out of hospital and assess their chances of survival.

\section{Participants, methods, and results}

In Aarhus (population 330 000), one mobile emergency care unit, staffed with an anaesthetist, runs in addition to ambulances and is dispatched in the most severe cases. From the databases of the mobile unit and the trauma centre, we identified severely injured patients who were intubated out of hospital (table). We defined a severely injured patient as having an injury severity score greater than 15 .

Between 1998 and 2000, the trauma team was activated in a total of 741 cases, and 220 patients were severely injured. The mobile unit brought 172 of these to hospital, and prehospital intubation was done in $43 \%(74 / 172)$ of severely injured patients. Of these, $84 \%(62 / 74)$ received anaesthetics. Fifty eight per cent $(36 / 62)$ of patients who were given anaesthetics and $8 \%(1 / 12)$ of patients who were not survived at least six months $(\mathrm{P}=0.003$, Fisher's exact test $)$.

\section{Comment}

Prehospital intubation was done in $43 \%$ of severely injured patients, mostly with anaesthesia; only 12 intubations were done without anaesthesia during three years, and although survival was considerably lower in this group, it was not negligible. The helicopter emergency medical service in London found pre-

\section{Patients intubated out of hospital}

\begin{tabular}{lcc} 
Characteristic & Given anaesthetics $(\mathbf{n}=\mathbf{6 2})$ & Not given anaesthetics $(\mathbf{n}=\mathbf{1 2})$ \\
\hline Mean (range) age & $35(0-78)$ & $30(5-76)$ \\
\hline Median (range) injury severity score & $29.5(16-59)$ & $32(16-75)$ \\
\hline Median (range) Glasgow coma scale score & $3.5(3-15)$ & $3(3-5)$ \\
\hline No of survivors & $36^{*}$ & 1 \\
\hline$\%$ survival rate (95\% confidence interval) & $58.1(44.9$ to 70.5$)$ & $8.3(0.2$ to 38.5$)$ \\
\hline
\end{tabular}


hospital intubation without drugs was hopeless, ${ }^{3}$ but we found that $8 \%$ of patients survived. The number was small, with the lower limit of the confidence interval of $0.2 \%$ just equal to the mean survival reported by the helicopter service.

Anaesthesia and intubation can be complicated by head and facial injuries, cervical fractures, risk of oesophageal intubation, aspiration, circulatory deterioration, and increased intracerebral pressure. The environment out of hospital is different from in hospital and support and resources are limited. We question whether anaesthesia and intubation of trauma patients can be mastered and routine be maintained by ambulance personnel.
Contributors: Both authors designed the study, did the statistical analysis, and wrote and revised the manuscript. CCSH collected the data. EFC is guarantor.

Funding: No additional funding.

Competing interests: None declared.

1 Sethi D, Kwan I, Kelly AM, Roberts I, Bunn F (on behalf of the WHO PreHospital Trauma Care Steering Committee). Advanced trauma life support training for ambulance crews. Cochrane Library. Issue 2. Oxford: Update Software, 2003: CD003109.

2 Liberman M, Mulder D, Sampalis J. Advanced or basic life support for trauma: meta-analysis and critical review of the literature. J Trauma 2000;49:584-99.

Lockey D, Davies G, Coats T. Survival of trauma patients who have prehospital tracheal intubation without anaesthesia or muscle relaxants: observational study. BMJ 2001;323:141

(Accepted 13 May 2003)

\title{
Risk of adenocarcinoma in Barrett's oesophagus: population based study
}

\author{
Liam Murray, Peter Watson, Brian Johnston, James Sloan, Inder Mohan Lal Mainie, Anna Gavin
}

Northern Ireland Cancer Registry, Department of Epidemiology and Public Health, Public Health, of Belfast, Belfast BT12 6BJ

Anna Gavin director

Liam Murray senior lecturer in epidemiology

Royal Hospitals Trust, Belfast BT12 6BA

Peter Watson consultant gastroenterologist Brian Johnston consultant gastroenterologist

James Sloan

consultant pathologis

Ulster Hospital,

Dundonald, Belfast BT16 1RB

Inder Mohan Lal

Mainie

specialist registrar in gastroenterology

Correspondence to: L Murray

l.murray@qub.ac.uk

BMJ 2003;327:534-5
Endoscopic surveillance of Barrett's oesophagus is now routine. ${ }^{1}$ Cost effectiveness depends on the risk of oesophageal adenocarcinoma. ${ }^{2}$ The magnitude of this risk is unclear because most previously published studies were small and inconclusive. ${ }^{3}$ Except for one, ${ }^{4}$ these studies were not population based but investigated patients at one or more centres. Selection bias or the effect of common losses to follow up were not assessed. ${ }^{5}$ We investigated the risk of oesophageal malignancy in a large cohort of unselected patients with Barrett's oesophagus in Northern Ireland, where all incident cancers are routinely identified.

\section{Participants, methods, and results}

We examined the pathology reports relating to all oesophageal biopsies in Northern Ireland between January 1993 and December 1999. We included every adult identified within Northern Ireland (population 1.7 million) as having oesophageal columnar epithelium. We excluded biopsies taken at the oesophagogastric junction.

We defined Barrett's oesophagus as the presence of columnar metaplasia in the oesophagus irrespective of whether Barrett's mucosa was reported (although we used this fact to further classify the biopsies as "macroscopic Barrett's oesophagus" or otherwise). We did not use data on segment length because it was often absent from reports. We subdivided biopsies finding Barrett's oesophagus further if the pathologist specifically stated that specialised intestinal metaplasia or goblet cells were definitely present or absent. We excuded malignant biopsies.

We identified patients in the cohort and followed them up for death and oesophageal malignancy (oesophageal adenocarcinoma and histologically unspecified oesophageal carcinomas or malignancies) until the end of 2000 by matching with death records from the Registrar General's Office and the Northern Ireland Cancer Registry's database of incident cancers.
We excluded oesophageal malignancies diagnosed within six months of the initial biopsy. We identified all patients in Northern Ireland with Barrett's oesophagus who had an oesophagectomy or ablative treatment for high grade dysplasia between January 1993 and December 2000. We calculated person years of follow up until diagnosis of the malignancy, death, or 31 December 2000. We estimated confidence intervals from the Poisson distribution.

Between 1993 and 1999, of 15670 oesophageal biopsies, 4955 (from 2969 patients) met our criteria for Barrett's oesophagus (table). The mean follow up was 3.7 (range 1 to 8 ) years, with 11068 person years of follow up. We found 29 oesophageal malignancies in the cohort. Four patients had an oesophagectomy for high grade dysplasia and two had ablative laser treatment. Oesophageal malignancy was $0.26 \%(0.18 \%$ to $0.38 \%)$ a year overall and $0.4 \%(0.26 \%$ to $0.59 \%)$ a year for patients with specialised intestinal metaplasia. The malignancy rate in men was 2.5 times that in women. Only for men older than 70 with specialised intestinal metaplasia was incidence greater than $1 \%$ per year.

\section{Comment}

Patients with Barrett's oesophagus are at low risk of oesophageal adenocarcinoma, and this risk is almost exclusively in patients with specialised intestinal metaplasia. Surveillance of patients with Barrett's oesophagus at a risk of malignant transformation of $1 \%$ per year may be cost effective, ${ }^{2}$ but only men aged 70 or more are at this risk, and limiting surveillance to them would miss two thirds of cancers. The length of follow up in our study was brief, but up to eight years after diagnosis we found no increased risk of malignancy with time (data available from authors).

Robust methods for stratifying risk and targeting surveillance in Barrett's oesophagus are needed. Although we did not use specific protocols for 